Pradat $P$ và cộng sự trên 50 bệnh nhân viêm gan $\mathrm{B}$ mạn điều trị TDF > 48 tuần nhận thấy rằng mức eGFR trung bình ở cuối theo dõi thấp hơn lúc ban đầu ( $-6 \mathrm{~mL} / \mathrm{phút} / 1,73 \mathrm{~m} 2)$ [4].

Trong nghiên cứu của Woo Jin Jung và cộng sự (2018), ở 110 bệnh nhân điều trị TDF kéo dài $>48$ tuần cũng ghi nhận mức creatinine đã tăng đáng kể ở 12, 24, 48, 72 và 96 tuần, trong khi mức eGFR cũng giảm có ý nghĩa tại 5 thời điểm này $(p<0,001)[7]$.

Nghiên cứu của chúng tôi cũng đã nhận thây sự gia tăng đáng kể mức creatinine trung bình ở thời điểm 24 và 48 tuần, đồng thời mức eGFR trung bình giảm có ý nghĩa tại thời điểm 24 tuần và 48 tuần so với mức ban đẩu với $\mathrm{p}<0.05$. Tuy nhiên nghiên cứu của chúng tôi còn hạn chế do là nghiên cứu hồi cứu, cỡ mẫu nhỏ, thời gian theo dõi mẫu ngắn.

Cũng theo hướng dẫn của Hiêp hội Nghiên cứu Gan châu Âu (EASL), tất cả bệnh nhân bắt đâu TDF nên được xét nghiệm nồng độ creatinine huyết thanh trước khi điêu trị [3]. Theo Hiệp hội Nghiên cứu bệnh gan Châu Á-Thái Bình Dương (APASL) 2016, do tiềm năng độc tính trên thận của TDF, nồng độ creatinine huyết thanh nên được theo dõi 3 tháng một lần trong khi điều trị bằng TDF [6].

\section{KẾT LUẬN}

Kết quả nghiên cứu chỉ ra chức năng thận giảm so với ban đầu ở bệnh nhân viêm gan $B$ mạn điều trị TDF, cho thấy chức năng thận cần được theo dõi thường xuyên ở những bệnh nhân đang điều trị với TDF.

\section{TÀI LIÊU THAM KHẢO}

1. Gallant JE, Deresinski S. Tenofovir disoproxil fumarate. Clin Infect Dis. 2013;37(7):944-950.

2. Goicoechea M, Liu S, Best B, Sun $S$, et al. Greater tenofovir-associated renal function decline with protease inhibitor-based versus nonnucleoside reverse-transcriptase inhibitor-based therapy. J Infect Dis. 2008;197:102-108.

3. EASL clinical practice guidelines. Management of chronic hepatitis B virus infection. J Hepatol. 2012;57(1):67-185.

4. Pradat $\mathbf{P}$, Le Pogam MA, Okon JB, Trolliet $\mathbf{P}$, et al. Evolution of glomerular filtration rate in HIVinfected, HIV-HBV-coinfected and HBV-infected patients receiving tenofovir disoproxil fumarate. J Viral Hepat. 2013; 20 (9): 650-657.

5. Koklu S, Gulsen $M T$, Tuna $Y$, Koklu $H$, et al. Differences in nephrotoxicity risk and renal effects among anti-viral therapies against hepatitis $\mathrm{B}$. Aliment Pharmacol Ther. 2015; 41 (3): 310-319.

6. Sarin SK, Kumar M, Lau GK, Abbas $Z$, et al (2016). Asian-Pacific clinical practice guidelines on the management of hepatitis B: a 2015 update. Hepatol Int. 2016;10 (1): 1-98.

7. Jung WJ, Jang JY, Park WY, Jeong SW, et al. Effect of tenofovir on renal function in patients with chronic hepatitis B. Medicine (Baltimore). 2018; 97(7): e9756.

8. Vittal A, Ghany MG. WHO Guidelines for Prevention, Care and Treatment of Individuals Infected with HBV: A US Perspective. Clin Liver Dis. 2019; 23(3): 417-432.

\title{
XÂY DỰNG QUY TRÌNH SẢN XUẤT MẪU HỒNG CẦU ỨNG DỤNG TRONG NGOẠI KIỂM XÉT NGHIỆM TRUYỀN MÁU
}

\author{
Vũ Quang Huy ${ }^{1,2}$, Huỳnh Thị Diễm Phúc ${ }^{2}$, Nguyễn Khánh Cường ${ }^{2}$
}

\section{TÓM TẮT}

Mục tiêu: Xây dựng quy trình sản xuất mẫu hồng cầu đổng thời đánh giá độ đồng nhất và ổn định của mẫu hồng cầu đáp ứng yểu cầu sử dụng trong ngoại kiểm xét nghiệm truyền máu. Phương pháp: 4 lô mẫu (50 mâu/lô) tương ứng với 4 nhóm máu hệ $A B O$ được sản xuất, 10 mẫu/lô được sử dung để đánh giá độ đồng nhất, 9 mẫu/lô được dùng để đánh giá độ ổn

${ }^{1}$ Đai học y dượ TP. Hồ Chí Minh

${ }^{2}$ Trung tâm Kiểm chuẩn chất lượng xét nghiệm Y học - Đai hoc Y Dước TP. Hồ Chí Minh

Chịu trách nhiệm chính: Vũ Quang Huy

Email: drvuquanghuy@gmail.com

Ngày nhận bài: 28.10 .2020

Ngày phản biên khoa học: 26.11.2020

Ngày duyệt băi: 3.12 .2020 định khi lưu trữ (49 ngày) và 3 mẫu/lô được dùng để đánh giá độ ổn định trong điều kiện vận chuyển (7 ngày). Các thông số kháng nguyên (antigen), số lượng hồng câu (RBC), hematocrit (Hct), hemoglobin (Hb), $\mathrm{Na}^{+}, \mathrm{K}^{+}$, lactate, lactate dehydrogenase (LDH) được dùng để đánh giá và theo dõi chất lượng mẫu. Kết quả: 4 bộ mẫu hồng cầu đã được sản xuất thành công và được đánh giá theo tiêu chuẩn ISO 17043:2010. Các bộ mẫu sản xuất đều đạt độ đồng nhất, ổn định tốt trong 35 ngày và vẫn đảm bảo các tiêu chuẩn thực hành lâm sàng cho đến ngày 49, chất lượng mẫu được đảm bảo trong 7 ngày ở điều kiện vận chuyển. Kết luâan: Xây dựng thành công quy trình sản xuất bộ mẫu hông câu theo tiêu chuấn của ISO 17043:2010. Mẫu hồng câu sản xuất đạt yêu câu chất lượng về độ đồng nhất và ổn định, có thể ứng dụng vào chương trình ngoại kiểm tra chất lượng xét nghiệm truyền máu. 
Tư khóa: ngoại kiểm, truyền máu, độ ổn định, độ đồng nhất.

\section{SUMMARY}

PROCEDURE OF RED BLOOD CELL PRODUCTION UTILIZING IN BLOOD TRANSFUSION EXTERNAL QUALITY ASSESSMENT PROGRAM

Objective: Development a procedure to produce red blood cell specimens and evaluate the homogeneity and stability of producing samples to meet the criteria for using in blood transfusion external quality assessment program. Methods: 4 lots of samples (50 samples / lot) corresponding to $4 \mathrm{ABO}$ blood groups are produced, 10 samples / lot are used to evaluate the homogeneity, 9 samples / lot are used to evaluate stability. in storage condition (49 days) and 3 samples / lot were used to assess stability in shipping conditions ( 7 days). Antigen, red blood cell count (RBC), hematocrit $(\mathrm{Hct})$, hemoglobin $(\mathrm{Hb}), \mathrm{Na}+, \mathrm{K}+$, lactate, lactate dehydrogenase (LDH) were used to evaluate and monitor sample's quality. Results: 4 sets of red blood cells were successfully produced and evaluated according to ISO 17043: 2010. The production samples are homogeneous, stable for 35 days and still ensure the standards of clinical practice until 49 days, sample quality is assured for 7 days under shipping conditions. Conclusion: The procedure of red blood cell production has successfully developed according to ISO 17043: 2010 standards. The producing samples meet the quality requirements of homogeneity and stability, and can be applied in the blood transfusion external quality assessment program.

Keywords: external quality assessment, blood transfusion, stability, uniformity.

\section{I. ĐẶT VẤN ĐỀ}

Hiện nay, cùng với sự phát triển về kinh tế, xã hội ngành y tế ngày càng được quan tâm. Vấn đề chăm sóc sức khỏe cho người dân ngày càng được chú trọng với những yêu cầu cao hơn. Vì vậy, để trở thành một cơ sở khám chữa bệnh thu hút được đông đảo người dân tin cậy, thách thức đặt ra là cân phải cung cấp những dịch vụ uy tín, chất lượng, trong đó có dịch vụ chất lượng xét nghiệm. Theo quyết định số $316 / \mathrm{TTg}$ ban hành ngày 27/02/2016 về việc phê duyệt đề án tăng cường năng lực quản lý chất lượng xét nghiệm y học giai đoạn 2016 - 2025 [1]. Với mục tiêu nâng cao chất lượng xét nghiệm y học, bảo đảm kết quả xét nghiệm chính xác, ḳ̣p thời. Đồng thời, làm cơ sở cho việc liên thông, công nhận kết quả xét nghiệm giữa các cơ sở y tế có thực hiện xét nghiệm. Bên cạnh đó còn tiết kiệm chi phí cho người bệnh, kinh tế xã hội, hội nhập mạng lưới kiểm chuẩn chất lượng xét nghiệm trong khu vực và trên thế giới.

Như chúng ta đã biết, các xét nghiệm trước truyền máu cực kỳ quan trọng trong việc cung cấp một đơn vị máu phù hợp và an toàn cho người nhận máu. Các sai sót có thể xảy ra ở bất kỳ quá trình nào trong các giai đoạn: thu thập máu từ người hiến máu, sàng lọc máu, phẩn phối các chễ phẩm, xét nghiệm máu người cho và người nhận, việc sai sót gây ảnh hưởng nghiêm trơng đến tính mạng con người.

Để triển khai chương trình ngoại kiểm truyền máu, đòi hỏi phải có một mẫu tiêu chuẩn, mẫu này được gửi đến tất cả các đơn vị tham gia ngoại kiểm. Nhưng hiện nay, ở Việt Nam vần chưa có đơn vị nào tự sản xuất, phần lớn các loại mẫu được nhập khẩu từ nước ngoài với giá thành cao, nguồn cung cấp mẫu không ổn định, gây trở ngại lớn về mặt tài chính cho các đơn vị "đang" tham gia và "mong muốn" tham gia ngoại kiểm. Với mục tiêu sản xuất và cung cấp bộ mẫu đạt tiêu chuẩn, chất lượng cao cho các đớn vị có thực hiện các kỹ thuật xét nghiệm truyền máu trong nước, chúng tôi tiến hành đề tài: "Xây dựng quy trình sản xuất mẫu hồng cầu ứng dụng trong ngoại kiểm xét nghiệm truyền máu". Mục tiêu nghiền cứu: Xây dựng quy trình sản xuất mẫu hồng cầu đạt tiêu chuẩn ISO/IEC 17043:2010 [2] ứng dụng trong chương trinh ngoại kiểm truyền máu.

Bộ mẫu hồng cầu đảm bảo đạt tính đồng nhất và ổn định [4] để cung cấp cho chương trình ngoại kiểm truyền máu.

\section{II. ĐỐI TƯợNG VÀ PHƯƠNG PHÁP NGHIÊN CỨU}

Thiết kế nghiên cứu. Nghiên cứu thực nghiệm.

Đối tượng nghiên cứu. Mẫu máu toàn phần nhận từ Trung tâm Truyền máu Bệnh viện Chợ Rẫy - Thành phố Hồ Chí Minh được đảm bảo vồ khuẩn, đã sàng lọc HIV, HBV, HCVV, Giang mai, Sốt rét.

Cỡ mẫu nghiên cứu. Cỡ mẫu tối thiểu cho nghiên cứu là 22 mẫu cho mỗi nhóm máu: $A, B$, $A B$ và $O$ theo tiêu chuẩn ISO 17043:2010 với số mẫu được đánh giá độ đồng nhất: 10 mẫu; số mẫu được đánh giá độ ổn định ngắn hạn 3 mẫu/ nhóm tổng cộng là 3 mẫu; dài hạn 3 mẫu/ thời điểm/ nhóm tổng cộng là 9 mẫu.

Để thuận tiện trong nghiên cứu và tránh lạc mất mẫu, chúng tôi sản xuất 50 mẫu cho mỗi nhóm: $A, B, A B$ và $O$.

Mẫu hồng cầu: 50 mẫu $x 4$ nhóm $=200$ mẫu

Tiêu chuẩn chọn mẫu. Các túi máu đã được xét nghiệm sàng lọc, âm tính với HIV, HBV, HCV tại Trung tâm Truyền máu Bệnh viện Chợ Rẫy trong thời gian từ tháng 09/2018 đến tháng 04/2019. Mẫu máu có Coombs trực tiếp và gián tiếp âm tính với phần thể tích $250-450$ mL, 
chống đông bằng chất CPDA, không bị tán huyết, không vón cục và được sản xuất không quá 07 ngày [7].

\section{Phương pháp}

Thu thập và xử lí số liệu. Nghiên cứu sẽ được tiến hành chọn mẫu và thu thập số liệu sau khi được sự chấp thuận của Hội đồng xét duyệt đề cương và Hội đồng y đức của Trường Đại học Y Dược Thành phố Hồ Chí Minh.

Số liệu được thu thập từ các kết quả xét nghiệm trong quá trình theo dõi độ đồng nhất và ổn định của mầu.

Số liệu được xử lý bằng phần mềm Microsoft Excel 2010, biểu diển dưới dạng chỉ số trung bình, độ lệch chuẩn và độ biến thiên.

\section{Tiến hành}

Chuẩn bị nguyên liệu thô. Nguyên liệu được lấy từ các túi máu toàn phần/ hồng cầu lắng/huyết tương nhương từ Ngân hàng máu Bệnh viện Chợ Rẫy, phù hợp với các quy định hiện hành. Không có hiện tượng tiêu huyết hay ngưng kêt sau khi ly tâm, không có kháng thể bất thường trên bề mặt tế bào hồng cầu và huyết tương.

Tách và làm sạch nguyên liệu. Các túi máu toàn phần thuộc các nhóm máu $A, B, O, A B$ được quay ly tâm 3 lần để tách huyết cầu và huyết tương với vận tốc 2000 vòng/phút/5 phút. Tách lấy huyết cầu và đem rửa với nước muối sinh lý 2 đến 3 lần, quay ly tâm 2000 vòng/ phút trong 5 phút sau mối lần rửa để loại bỏ dịch nổi và loại lớp buffy coat (Bạch cầu, Tiểu cầu). Sau đó, pha huyền dịch hồng cầu $5 \%$ treo trong dung dịch bảo quản hồng cầu, trộn đều và phân phối vào các ống nghiệm nhựa vồ trùng ( $2 \mathrm{~mL} / o ̂ ́ n g)$ đậy kín nắp bảo quản ở nhiệt độ 2-6º

Thời gian theo dỗi mẫu nghiên cứu

Mẫu nghiên cứu được đánh giá để đảm bảo độ đồng nhất ở ngày đầu tiên sản xuất. Độ ổn định được theo dôii trong suốt thời gian diễn ra chương trình ngoại kiểm qua các mốc thời gian: 0 ngày, 7 ngày, 35 ngày, 42 ngày và 49 ngày.

Phương pháp đo: $\mathrm{Hct}, \mathrm{Hb}, \mathrm{Na}^{+}, \mathrm{K}^{+}$, Lactate, $\mathrm{LDH}, \mathrm{FHb}$

Hct và $\mathrm{Hb}$ được đo bằng máy huyết học tự động hoạt động theo phương pháp tổng trở và laser. Nồng độ $\mathrm{Na}^{+}, \mathrm{K}^{+}$, Lactate, LDH được đo bằng hệ thống máy sinh hóa tự động. $\mathrm{FHb}$ được đo bằng Human free haemoglobin ( $\mathrm{f}-\mathrm{Hb}$ ) ELISA Kit. Tất cả các thông số này được nội kiểm và ngoại kiểm đạt chất lượng theo quy định.

Phương pháp đánh giá vô trùng. Các mẫu hồng cầu theo dõi độ vô trùng bằng cách cây 10 microlit mẫu cấy lên thạch $\mathrm{MHA}$ ủ $37^{\circ} \mathrm{C}$ trong vòng
14 ngày, theo dõi và đọc kết quả sau 14 ngày. Phương pháp đo độ đặc hiệu của kháng nguyên Độ đặc hiệu của kháng nguyên được thực hiên trực tiếp với Anti $A$, Anti $B$, Anti $A B$. Ngưng kết 4+: 12 điểm; Ngưng kết $3+: 10$ điểm; Ngưng kết 2+: 8 điểm; Ngưng kết 1+: 5 điểm; Ngưng kết $\pm: 3$ điểm

Đánh giá độ đồng nhất của các mẫu. Lãy ngẫu nhiên 10 mẫu theo từng lô và đánh giá các thông số kiểm tra độ đồng nhất, dựa trên tiêu chuẩn Châu Âu và FDA Hoa Kỳ, với độ biến thiên giữa các mẫu $\mathrm{CV}<3,0 \%$ được xem là ổn định. Mức độ tiêu huyết được chia làm 4 cấp độ [7]:

Mức 0: không tiêu huyết ( $\mathrm{FHb}<500 \mathrm{mg} / \mathrm{L})$

Mức 1: tiêu huyết nhẹ $(500 \mathrm{mg} / \mathrm{L} \leq \mathrm{FHb}<$ $1000 \mathrm{mg} / \mathrm{L}$ )

Mức 2: tiêu huyết trung bình $(1000 \mathrm{mg} / \mathrm{L} \leq$ $\mathrm{FHb}<2000 \mathrm{mg} / \mathrm{L}$ ) $\mathrm{mg} / \mathrm{L}$ )

Mức 3: tiêu huyết nghiêm trọng (FHb $\geq 2000$

Nếu tình trạng tiêu huyết của bất kỳ mẫu nghiên cứu nào vượt quá mức 2 , thì mẫu xem như không đạt và không tham gia vào thử nghiệm.

Bên cạnh đó, một số chỉ số khác cũng được theo dõi độ đồng nhất mấu như: thể tích, kháng nguyên, $\mathrm{RBC}, \mathrm{Hct}, \mathrm{Hb}, \mathrm{Na}^{+}, \mathrm{K}^{+}$, Lactate, $\mathrm{LDH}$.

Đánh giá độ ổ định

Đánh giá độ ổn định của mẫu trong điều kiện ngắn hạn và dài hạn theo hướng dẫn của ISO/IEC 17043:2010.

Đánh giá ngắn hạn: Theo dõi mẫu từ ngày sản xuất (ngày 0 ) đến ngày 07 đặt trong điêu kiện $2^{\circ} \mathrm{C}-6^{\circ} \mathrm{C}$ tại $\mathrm{PXN}$, và mẫu được đặt trong điều kiên vận chuyển đến các đơn vị tham gia ngoại kiểm (nhiệt độ được duy trì trong khoảng từ $2^{\circ} \mathrm{C}-10^{\circ} \mathrm{C}$ ).

Đánh giá dài hạn: Theo dõi mẫu từ ngày sản xuất (ngày 0 ) đến ngày thứ 49 đặt trong điêu kiện $2^{\circ} \mathrm{C}-6^{\circ} \mathrm{C}$ tại PXN.

Mẫu đánh giá độ ổn định được chọn ngẫu nhiên 03 mẫu từ mỗi lô mẫu, được phân tích các thông số: Kháng nguyên (Antigen), RBC, Hct, $\mathrm{Hb}, \mathrm{Na}^{+}, \mathrm{K}^{+}$, Lactate, $\mathrm{LDH}$ vào các ngày $7,35,42$ và 49 [7].

\section{KẾT QUẢ NGHIÊN CỨU}

Kết quả đánh giá độ đồng nhất của mẫu hồng câu. Kết quả cho thấy, $\mathrm{A}$ - antigen đạt 12 điểm; số lượng trung bình của hồng cầu giữa các mẫu là $502 \pm 9,19\left(10^{3} / \mathrm{uL}\right) ;$ Nồng độ Hct 4,9 $\pm 0,08$ (\%); Nồng độ $\mathrm{Hb} 1,48 \pm 0,06(\mathrm{~g} / \mathrm{dL}) ; \mathrm{Na}^{+}$ $145 \pm 1.15$ (mmol/L); $\mathrm{K}^{+} 4,01 \pm 0,17(\mathrm{mmol} / \mathrm{L}) ;$ $\mathrm{LDH} 209 \pm 3,22(\mathrm{U} / \mathrm{L}) ;$ Lactate 6,16 $\pm 0,3$ $(\mathrm{mg} / \mathrm{dL}) ; \mathrm{FHb} 0,008 \pm 0,001(\mathrm{mg} / \mathrm{L})$. Độ biến 
thiên giữa các mẫu CV\% dao động trong khoảng $0,015 \%$ đến $0,078 \%(<3,0 \%)$.

$\mathrm{B}$ - antigen đạt 12 điểm; số lượng $\mathrm{HC}$ trung bình là $492 \pm 12,3\left(10^{3} / \mathrm{uL}\right) ;$ Hct 4,83 $\pm 0,08$ (\%); Nồng độ $\mathrm{Hb} 1,43 \pm 0,09(\mathrm{~g} / \mathrm{dL}) ; \mathrm{Na}^{+} 143,4$ $\pm 2,63(\mathrm{mmol} / \mathrm{L}) ; \mathrm{K}^{+} 4,89 \pm 0,13(\mathrm{mmol} / \mathrm{L}) ; \mathrm{LDH}$ $209 \pm 3,4(\mathrm{U} / \mathrm{L}) ;$ Lactate $6,08 \pm 0,11(\mathrm{mg} / \mathrm{dL}) ;$ $\mathrm{FHb} 0,003 \pm 0,001(\mathrm{mg} / \mathrm{L})$. CV\% từ 0,016 \% đến $0,222 \%(<3,0 \%)$.

$\mathrm{AB}$ - antigen đạt 12 điểm; Số lượng $\mathrm{HC}$ trung bình là $499 \pm 11\left(10^{3} / \mathrm{uL}\right) ;$ Hct 4,89 $\pm 0,09(\%)$; $\mathrm{Hb} 1,46 \pm 0,07(\mathrm{~g} / \mathrm{dL}) ; \quad \mathrm{Na}^{+} \quad 147,6 \pm 2,37$
(mmol/L); K $\mathrm{K}^{+} 4,0 \pm 0,18$ (mmol/L); LDH 209,4 $\pm 4,12(\mathrm{U} / \mathrm{L}) ;$ Lactate $6,24 \pm 0,32(\mathrm{mg} / \mathrm{dL}) ; \mathrm{FHb}$ $0,004 \pm 0,001$ (mg/L). CV\% dao động trong khoảng $0,016 \%$ đến $0,14 \%(<3,0 \%)$.

Ở bộ mẫu hồng cầu $O$ trung bình của hồng cầu giữa các mẫu là $496 \pm 7\left(10^{3} / \mathrm{uL}\right)$; Nồng độ Hct 4,87 $\pm 0,08$ (\%); Nồng độ $\mathrm{Hb}$ 1,45 $\pm 0,05$ $(\mathrm{g} / \mathrm{dL}) ; \mathrm{Na}^{+} 145,6 \pm 1,71(\mathrm{mmol} / \mathrm{L}) ; \mathrm{K}^{+} 3,99 \pm 0,16$ (mmol/L); LDH 209,5 $\pm 2,45(\mathrm{U} / \mathrm{L}) ;$ Lactate 6,16 $\pm 0,3$ (mg/dL); FHb 0,001 $\pm 0,000$ (mg/L). Độ biến thiên giữa các mẫu CV\% dao động trong khoảng $0,012 \%$ đến $0,111 \%(<3,0 \%)$.

Bảng 1. So sánh độ đồng nhât qua độ biên thiên giữa 4 nhóm $A, B, A B, O$

\begin{tabular}{|c|c|c|c|c|c|c|c|c|c|c|}
\hline $\begin{array}{l}\text { Nhóm } \\
\text { máu }\end{array}$ & $\mathbf{N}=10$ & \begin{tabular}{|l} 
Antigen \\
(Score)
\end{tabular} & $\begin{array}{c}\text { RBC } \\
10^{\wedge} 3 / \mathrm{uL} \\
\end{array}$ & $\begin{array}{l}\text { Hct } \\
(\%)\end{array}$ & $\begin{array}{c}\mathrm{Hb} \\
(\mathrm{g} / \mathrm{dL})\end{array}$ & $\begin{array}{c}\mathrm{Na}+ \\
(\mathrm{mmol} / \mathrm{L})\end{array}$ & $\begin{array}{c}\mathrm{K}+ \\
(\mathrm{mmol} / \mathrm{L}) \\
\end{array}$ & $\begin{array}{l}\text { LDH } \\
\text { (U/L) }\end{array}$ & $\begin{array}{l}\text { Lactate } \\
\text { (mg/dL) }\end{array}$ & $\begin{array}{c}\mathbf{F H b} \\
(\mathrm{mg} / \mathrm{L})\end{array}$ \\
\hline Nhóm & MEAN & 12 & 499 & 4,89 & 1,46 & 147,6 & 4 & 209,4 & 6,24 & 0,0043 \\
\hline$A B$ & CV\% & 0 & 0,022 & 0,018 & 0,048 & 0,016 & 0,045 & 0,02 & 0,051 & 0,14 \\
\hline Nhóm & MEAN & 12 & 496 & 4,87 & 1,45 & 145,6 & 3,99 & 209,5 & 6,16 & 0,0009 \\
\hline 0 & CV\% & 0 & 0,014 & 0,016 & 0,034 & 0,012 & 0,04 & 0,012 & 0,049 & 0,111 \\
\hline Nhóm & MEAN & 12 & 492 & 4,83 & 1,43 & 143,4 & 4,89 & 209 & 6,08 & 0,0027 \\
\hline B & CV\% & 0 & 0,025 & 0,017 & 0,063 & 0,018 & 0,027 & 0,016 & 0,018 & 0,222 \\
\hline Nhóm & MEAN & 12 & 502 & 4,9 & 1,48 & 145 & 4,01 & 209 & 6,16 & 0,0077 \\
\hline A & CV\% & 0 & 0,018 & 0,016 & 0,041 & 0,008 & 0,042 & 0,015 & 0,049 & 0,078 \\
\hline
\end{tabular}

Kết quả cho thấy, Antigen của cả 4 nhóm đều đạt 12 điểm, RBC dao động 496 - $502\left(10^{3} / \mathrm{uL}\right)$; Hct dao động 4,83-4,9 (\%); Nồng độ $\mathrm{Hb}$ dao động $1,43-1,48(\mathrm{~g} / \mathrm{dL}) ; \mathrm{Na}^{+}$dao động $143,4-$ $147,6(\mathrm{mmol} / \mathrm{L}) ; \mathrm{K}^{+}$dao động 3,99 - 4,89 (mmol/L); LDH dao động 209 - 209,4 (U/L); Lactate dao động 6,08 - 6,24 (mg/dL); FHb dao động 0,001 - 0,008 (mg/L).

Đô biến thiên $\mathrm{CV} \%$ của $\mathrm{RBC}$ tốt giảm dần từ $\mathrm{O}>\mathrm{A}>\mathrm{AB}>\mathrm{B} ; \mathrm{CV} \%$ của Hct tốt giảm dần từ $\mathrm{O}$ $=A>B>A B ; C V \%$ của $\mathrm{Hb}$ tốt giảm dần từ $O>$ $A>A B>B ; C V \%$ của $\mathrm{Na}^{+}$tốt giảm dần từ $A>$
$O>A B>B ; C V \%$ của $K^{+}$tốt giảm dần từ $B>O>$ $A>A B ; C V \%$ của $L D H$ tốt giảm dần từ $O>A>B$ $>A B ; C V \%$ của Lactate tốt giảm dần từ $B>0=$ $A>A B ; C V \%$ tốt giảm dần từ $A>0>A B>B$.

Kết quả đánh giá độ ổn định ngắn hạn mẫu hồng câu. Kết quả cho thấy sự khác biệt không nhiều giữa mẫu được đặt tại điều kiện bảo quản $2-6^{\circ} \mathrm{C}$ và mẫu được đặt tại điều kiện vận chuyển $2-10^{\circ} \mathrm{C}$ trong 7 ngày. Nhóm $O, B, A B$ có $\mathrm{CV} \%$ dao động từ 0 đến 0.044 . Riêng nhóm $\mathrm{A}$ có CV dao động từ 0 đến 0.02 .

\section{Bảng 2: Kêt quả độ ổn định ngắn hạn của mẫu hồng cầu sản xuât}

\begin{tabular}{|c|c|c|c|c|c|c|c|c|c|}
\hline \multicolumn{2}{|c|}{ NHÓM } & \multicolumn{2}{c|}{ Nhóm A } & \multicolumn{2}{c|}{ Nhóm B } & \multicolumn{2}{c|}{ Nhóm AB } & \multicolumn{2}{c|}{ Nhóm O } \\
\hline $\mathrm{N}=3$ & & Mean & CV\% & Mean & CV\% & Mean & CV\% & Mean & CV\% \\
\hline \multirow{2}{*}{$\mathrm{Na}^{+}$} & 1 & 140 & 0.004 & 139 & 0.011 & 134 & 0.038 & 139 & 0.012 \\
\cline { 2 - 10 } & 2 & 132 & 0.02 & 132 & 0.031 & 132 & 0.027 & 133 & 0.019 \\
\hline \multirow{2}{*}{$\mathrm{K}^{+}$} & 1 & 4.6 & 0.026 & 4.5 & 0.013 & 4.6 & 0.026 & 5.1 & 0.012 \\
\cline { 2 - 10 } & 2 & 4.7 & 0.032 & 4.7 & 0.032 & 4.8 & 0.044 & 4.7 & 0.044 \\
\hline \multirow{2}{*}{$\begin{array}{c}\text { Antigen } \\
(\text { Score })\end{array}$} & 1 & 12 & 0 & 12 & 0 & 12 & 0 & 0 & 0 \\
\cline { 2 - 10 } RBC & 1 & 42 & 0 & 12 & 0 & 12 & 0 & 0 & 0 \\
\cline { 2 - 10 }$\left(10^{\wedge} 3 / \mathrm{uL}\right)$ & 2 & 484 & 0.031 & 483 & 0.012 & 493 & 0.012 & 492 & 0.06 \\
\hline \multirow{2}{*}{$\mathrm{Hct}(\%)$} & 1 & 4.8 & 0.013 & 478 & 0.016 & 486 & 0.012 & 489 & 0.01 \\
\cline { 2 - 10 } & 2 & 4.77 & 0.122 & 4.7 & 0.021 & 4.83 & 0.012 & 4.9 & 0 \\
\hline \multirow{2}{*}{$\mathrm{Hb}(\mathrm{g} / \mathrm{dL})$} & 1 & 1.43 & 0.042 & 1.36 & 0.044 & 1.43 & 0.042 & 1.4 & 0 \\
\cline { 2 - 10 } & 2 & 1.47 & 0.039 & 1.4 & 0 & 1.43 & 0.042 & 1.37 & 0.044 \\
\hline
\end{tabular}

Kết quả đánh giá độ ổn định dài hạn mẫu hồng câu. ở hồng cầu nhóm $A$, kết quả nghiên cứu từ ngày 0 đến ngày 49 cho thây, có sự biến động ở các thông số được theo dõi. A - 
antigen đạt 12 điểm; số lượng trung bình của $\mathrm{HC}$ giữa các thời điểm giảm: 502 - $453\left(10^{3} / \mathrm{uL}\right)$; Nồng độ Hct 4,9 - 4,6 (\%); Nồng độ $\mathrm{Hb} 1,48$ $1,2(\mathrm{~g} / \mathrm{dL}) ; \mathrm{Na}^{+} 145-118,67(\mathrm{mmol} / \mathrm{l}) ; \mathrm{K}^{+}$tăng 4,01 - 7,7 (mmol/L); LDH tăng $209-290$ (U/L); Lactate tăng $6,16-10,4(\mathrm{mg} / \mathrm{dL})$. Độ biến thiên giữa các mẫu $\mathrm{CV} \%$ dao động trong khoảng $0,004 \%$ đến $0,079 \%(<3,0 \%)$.

Ở hồng cầu nhóm $\mathrm{B}$, kết quả nghiên cứu từ ngày 0 đến ngày 49 cho thấy, có sự biến động ở các thông số được theo dõi. A - antigen đạt 12 điểm; số lơợng trung bình của hồng cầu giữa các thời điểm giảm: $492-453,33\left(10^{3} / \mathrm{uL}\right)$; Nồng độ Hct 4,83 - 4,6 (\%); Nồng độ $\mathrm{Hb} 1,43-1,2$ $(\mathrm{g} / \mathrm{dL}) ; \mathrm{Na}^{+} 143,4-118,33(\mathrm{mmol} / \mathrm{L}) ; \mathrm{K}^{+}$tăng 4,89 - 7,83 (mmol/L); LDH tăng $209-286$ (U/L); Lactate tăng $6,08-10,77(\mathrm{mg} / \mathrm{dL})$. Độ biến thiên giữa các mẫu $\mathrm{CV} \%$ dao động trong khoảng $0,006 \%$ đến $0,032 \%(<3,0 \%)$.

Ở hồng câu nhóm $A B$, kết quả nghiên cứu từ ngày 0 đến ngày 49 cho thấy, co sự biến động ở các thông số được theo dõi. A, B - antigen đạt 12 điểm; số lượng trung bình của hồng cầu giữa các thời điểm giảm: 499 - $416\left(10^{3} / \mathrm{uL}\right)$; Nồng độ Hct 4,89 - 4,03 (\%); Nồng độ $\mathrm{Hb} 1,46-1,2$ $(\mathrm{g} / \mathrm{dL}) ; \mathrm{Na}^{+} 147,6-116,33(\mathrm{mmol} / \mathrm{L}) ; \mathrm{K}^{+}$tăng 4,0 - 7,93 (mmol/L); LDH tăng 209,4 - 289,67 $(\mathrm{U} / \mathrm{L})$; Lactate tăng $6,24-13,43(\mathrm{mg} / \mathrm{dL})$. Độ biến thiên giữa các mẫu $\mathrm{CV} \%$ dao động trong khoảng $0,005 \%$ đến $0,038 \%(<3,0 \%)$.

ở hồng cầu nhóm $O$, kết quả nghiên cứu từ ngày 0 đến ngày 49 cho thây, co sự biến động ở các thông số được theo dõi. Số lượng trung bình của hồng cầu giữa các thời điểm giảm: 496 - 403 $\left(10^{3} / \mathrm{uL}\right)$; Nồng độ Hct 4,87 - 4,00 (\%); Nồng độ $\mathrm{Hb} 1,45-1,13(\mathrm{~g} / \mathrm{dL}) ; \mathrm{Na}^{+} 145,6-115,33$ (mmol/L); $\mathrm{K}^{+}$tăng $3,99-7,7(\mathrm{mmol} / \mathrm{L}) ; \mathrm{LDH}$ tăng $209,5-282(\mathrm{U} / \mathrm{L})$; Lactate tăng $6,16-10(\mathrm{mg} / \mathrm{dL})$. Độ biến thiên giữa các mẫu CV \% dao động trong khoảng $0,005 \%$ đến $0,05 \%$ (<3,0\%).

\section{Bảng 3: Kêt quả độ ổn định dài hạn của mẫu hồng cầu sản xuât}

\begin{tabular}{|c|c|c|c|c|c|c|c|c|c|}
\hline \multirow{2}{*}{$\begin{array}{c}\text { Thông } \\
\text { số }\end{array}$} & \multirow{2}{*}{ Ngày } & \multicolumn{2}{|c|}{ Nhóm A } & \multicolumn{2}{|c|}{ Nhóm B } & \multicolumn{2}{|c|}{ Nhóm AB } & \multicolumn{2}{|c|}{ Nhóm 0} \\
\hline & & Mean & SD & Mean & SD & Mean & SD & Mean & SD \\
\hline \multirow{5}{*}{$\begin{array}{l}\text { Kháng } \\
\text { nguyên } \\
\text { (điêm) }\end{array}$} & 0 & 12 & \pm 0 & 12 & \pm 0 & 12 & \pm 0 & 0 & \\
\hline & 7 & 12 & \pm 0 & 12 & \pm 0 & 12 & \pm 0 & 0 & \\
\hline & 35 & 12 & \pm 0 & 12 & \pm 0 & 12 & \pm 0 & 0 & \\
\hline & 42 & 12 & \pm 0 & 12 & \pm 0 & 12 & \pm 0 & 0 & \\
\hline & 49 & 12 & \pm 0 & 12 & \pm 0 & 12 & \pm 0 & 0 & \\
\hline \multirow{5}{*}{$\begin{array}{c}\text { RBC } \\
\left(10^{3} / \mu L\right)\end{array}$} & 0 & 502 & $\pm 9,2$ & 492 & $\pm 12,3$ & 499 & $\pm 11,0$ & 496 & $\pm 7,0$ \\
\hline & 7 & 493 & $\pm 15,3$ & 483 & $\pm 5,8$ & 493 & $\pm 5,8$ & 492 & $\pm 2,9$ \\
\hline & 35 & 493 & $\pm 15,3$ & 482 & $\pm 2,9$ & 486 & $\pm 1,7$ & 487 & $\pm 2,5$ \\
\hline & 42 & 457 & $\pm 5,8$ & 457 & $\pm 5,8$ & 450 & $\pm 10,0$ & 428 & $\pm 8,0$ \\
\hline & 49 & 453 & $\pm 5,8$ & 453 & $\pm 5,8$ & 416 & $\pm 5,8$ & 403 & $\pm 6,1$ \\
\hline \multirow{5}{*}{ Hct (\%) } & 0 & 4,90 & $\pm 0,08$ & 4,83 & $\pm 0,08$ & 4,89 & $\pm 0,09$ & 4,87 & $\pm 0,08$ \\
\hline & 7 & 4,80 & $\pm 0,06$ & 4,77 & $\pm 0,06$ & 4,83 & $\pm 0,06$ & 4,90 & $\pm 0,0$ \\
\hline & 35 & 4,80 & $\pm 0,06$ & 4,77 & $\pm 0,06$ & 4,77 & $\pm 0,06$ & 4,80 & $\pm 0,0$ \\
\hline & 42 & 4,60 & $\pm 0,06$ & 4,63 & $\pm 0,06$ & 4,60 & $\pm 0,10$ & 4,30 & $\pm 0,10$ \\
\hline & 49 & 4,60 & $\pm 0,0$ & 4,60 & $\pm 0,0$ & 4,03 & $\pm 0,06$ & 4,00 & $\pm 0,0$ \\
\hline \multirow{5}{*}{$\underset{(\mathrm{g} / \mathrm{dL})}{\mathrm{Hb}}$} & 0 & 1,48 & $\pm 0,06$ & 1,43 & $\pm 0,09$ & 1,46 & $\pm 0,06$ & 1,45 & $\pm 0,05$ \\
\hline & 7 & 1,43 & $\pm 0,06$ & 1,36 & $\pm 0,06$ & 1,43 & $\pm 0,07$ & 1,40 & $\pm 0,0$ \\
\hline & 35 & 1,43 & $\pm 0,06$ & 1,36 & $\pm 0,06$ & 1,33 & $\pm 0,06$ & 1,33 & $\pm 0,06$ \\
\hline & 42 & 1,20 & $\pm 0,0$ & 1,20 & $\pm 0,0$ & 1,33 & $\pm 0,06$ & 1,23 & $\pm 0,06$ \\
\hline & 49 & 1,20 & $\pm 0,0$ & 1,20 & $\pm 0,0$ & 1,20 & $\pm 0,06$ & 1,13 & $\pm 0,06$ \\
\hline \multirow{5}{*}{$\begin{array}{c}\mathrm{Na}^{+} \\
(\mathrm{mmol} / \mathrm{L})\end{array}$} & 0 & 145 & $\pm 1,2$ & 143 & $\pm 2,6$ & 148 & $\pm 2,4$ & 146 & $\pm 1,7$ \\
\hline & 7 & 140 & $\pm 0,6$ & 139 & $\pm 1,5$ & 134 & $\pm 5,1$ & 139 & $\pm 1,7$ \\
\hline & 35 & 134 & $\pm 1,2$ & 134 & $\pm 1,2$ & 134 & $\pm 2,1$ & 133 & $\pm 2,9$ \\
\hline & 42 & 128 & $\pm 2,5$ & 127 & $\pm 2,9$ & 124 & $\pm 1,7$ & 126 & $\pm 2,3$ \\
\hline & 49 & 119 & $\pm 3,2$ & 118 & $\pm 3,1$ & 116 & $\pm 2,5$ & 115 & $\pm 3,1$ \\
\hline \multirow{5}{*}{$\begin{array}{c}\mathrm{K}^{+} \\
(\mathrm{mmol} / \mathrm{L})\end{array}$} & 0 & 4,01 & $\pm 0,20$ & 4,89 & $\pm 0,10$ & 4,00 & $\pm 0,20$ & 3,99 & $\pm 0,16$ \\
\hline & 7 & 4,57 & $\pm 0,12$ & 4,53 & $\pm 0,06$ & 4,57 & $\pm 0,12$ & 5,13 & $\pm 0,06$ \\
\hline & 35 & 5,03 & $\pm 0,15$ & 5,03 & $\pm 0,15$ & 4,87 & $\pm 0,12$ & 5,00 & $\pm 0,06$ \\
\hline & 42 & 6,43 & $\pm 0,51$ & 6,33 & $\pm 0,15$ & 6,13 & $\pm 0,15$ & 6,17 & $\pm 0,31$ \\
\hline & 49 & 7,70 & $\pm 0,26$ & 7,83 & $\pm 0,30$ & 7,93 & $\pm 0,06$ & 7,70 & $\pm 0,36$ \\
\hline
\end{tabular}


VIETNAM MEDICAL JOURNAL N¹ - JANUARY - 2021

\begin{tabular}{|c|c|c|c|c|c|c|c|c|c|}
\hline & 0 & 209 & $\pm 3,22$ & 209 & $\pm 3,40$ & 209 & $\pm 4,12$ & 209 & $\pm 2,45$ \\
\cline { 2 - 9 } LDH & 7 & 218 & $\pm 2,89$ & 219 & $\pm 3,51$ & 221 & $\pm 2,65$ & 230 & $\pm 2,52$ \\
\cline { 2 - 9 }$(\mathrm{U} / \mathrm{L})$ & 35 & 254 & $\pm 4,04$ & 254 & $\pm 4,04$ & 260 & $\pm 1,53$ & 245 & $\pm 5,03$ \\
\cline { 2 - 9 } & 42 & 264 & $\pm 4,04$ & 265 & $\pm 4,51$ & 267 & $\pm 2,65$ & 261 & $\pm 4,58$ \\
\cline { 2 - 9 } & 49 & 290 & $\pm 10,05$ & 298 & $\pm 6,08$ & 290 & $\pm 1,53$ & 282 & $\pm 5,29$ \\
\hline \multirow{4}{*}{$\begin{array}{c}\text { Lactate } \\
\text { (mg/dL) }\end{array}$} & 0 & 6,16 & $\pm 0,30$ & 6,08 & $\pm 0,11$ & 6,24 & $\pm 0,32$ & 6,16 & $\pm 0,30$ \\
\cline { 2 - 9 } & 35 & 7,17 & $\pm 0,20$ & 7,23 & $\pm 0,23$ & 8,77 & $\pm 0,25$ & 7,37 & $\pm 0,23$ \\
\cline { 2 - 9 } & 42 & 8,97 & $\pm 0,12$ & 8,33 & $\pm 0,15$ & 11,67 & $\pm 0,35$ & 7,83 & $\pm 0,15$ \\
\cline { 2 - 9 } & 49 & 10,40 & $\pm 0,53$ & 10,80 & $\pm 0,10$ & 12,83 & $\pm 0,25$ & 8,73 & $\pm 0,25$ \\
\hline
\end{tabular}

RBC: Red blood cell; Hct: Hematocrit; Hb: Hemoglobin; LDH: Lactate dehydrogenase; SD: độ lệch chuân

Qua kết quả nghiên cứu cho thấy, tất cả mẫu ở 4 nhóm đều giữ được độ ổn định ở các đặc tính quan trọng có thể kiểm soát: Antigen, RBC, $\mathrm{Hct}, \mathrm{Hb}$ và nồng độ $\mathrm{Na}^{+}, \mathrm{K}^{+}$, Lactate, $\mathrm{LDH}$. Antigen trong mẫu từ ngày 0 đến ngày 49 đạt độ ổn định tốt duy trì ở mức 12 điểm. Dùng kiểm định t-test với $\mathrm{p}>0,05$ để kiểm tra độ ổn định của mẫu qua các giai đoạn, số lượng HC có sự biến động, theo kiểm định này số lượng $\mathrm{HC}$ ổn định 35 ngày $(p>0,05)$, đến ngày 49 số lượng HC giảm khoảng $10 \%$ so với ngày 0 . Tương tự, nồng độ $\mathrm{Hct}$ và $\mathrm{Hb}$ cũng duy trì ổn định từ ngày 0 đến ngày 35 , đến ngày 49 mẫu không còn đạt độ ổn định. Nồng độ $\mathrm{Na}^{+}$giảm xuống theo thời gian bảo quản ( 0 - 49 ngày): (145 mmol/L - 118,67 $\mathrm{mmo} / \mathrm{L}) . \mathrm{K}^{+}$tăng từ $4,01 \mathrm{mmol} / \mathrm{L}-7,70 \mathrm{mmol} / \mathrm{L}$. $\mathrm{LDH}$ tăng từ $209 \mathrm{mmol} / \mathrm{L}-290 \mathrm{mmol} / \mathrm{L}$. Lactate cũng tăng cao từ $6,16 \mathrm{mmol} / \mathrm{L}-10,40 \mathrm{mmol} / \mathrm{L}$.

Kết quả đánh giá độ vô trùng mẫu hồng câu

Bảng 4. Kêt quả đánh giá độ vô trùng mẫu hống cầu

\begin{tabular}{|c|c|c|c|}
\hline Nhóm A & Nhóm B & Nhóm AB & Nhóm O \\
\hline Âm tính & Âm tính & Âm tính & Âm tính \\
\hline Âm tính & Âm tính & Âm tính & Âm tính \\
\hline Âm tính & $\hat{A} m$ tính & Ám tính & Âm tính \\
\hline
\end{tabular}

Tất cả các mẫu hồng cầu khi cấy trên môi trường MHA ủ $37^{\circ} \mathrm{C}$ đều không có vi khuẩn mọc theo dõi trong thời gian 14 ngày.

\section{BÀN LUÂN}

Ngoại kiểm chất lượng xét nghiệm đóng vai trò vô cùng quan trong, với mục đích giám sát và nâng cao chất lượng các xét nghiệm, phát hiện các sai sót, tìm nguyên nhân và đọa ra các biện pháp khắc phục. Đồng thời, ngoại kiểm góp phần kiểm định chất lượng và năng lực của các phòng xét nghiệm. Để đảm bảo chương trình ngoại kiểm được triển khai có hiệu quả, chất lượng mẫu ngoại kiểm là mối quan tâm hàng đầu. Mẫu ngoại kiểm phải đảm bảo được hai đặc tính quan trọng nhất là: tính đồng nhất và tính ổn định [5], [6]. Độ đồng nhất sẽ đảm bảo các đơn vị nhận được các mẫu nhơ nhau để tiến hành phân tích và đọa ra các kết quả xét nghiệm khách quan. Độ ổn định đảm bảo cho các chỉ số cần phân tích của mẫu duy trì ở mức giới hạn, đạt tiêu chuẩn để trong thời gian bảo quản dài và̀ khả năng biến đổi thấp. Tốt nhất, các sản phẩm ngoại kiểm nên được giữ trong cùng điều kiện bảo quản với các mẫu nghiệm phẩm để hạn chế những sự khác biệt giữa các mấu ngoại kiểm và mẫu thông thường

Các xét nghiệm định nhóm máu, xét nghiệm hòa hợp, xét nghiệm tìm kháng thể và định danh kháng thể bất thường trong truyền máu, là các xét nghiệm nhằm kiểm tra hoạt động của phản ứng của kháng nguyên nhóm máu trên hồng cầu và kháng thể trong huyết thanh.

Đơn vị triển khai chương trình ngoại kiểm sẽ dựa vào giá trị đồng thuận giữa các phòng xét nghiệm tham gia thông qua so sánh liên phòng để đưa ra giá trị ấn định chung cho các kết quả xét nghiệm, làm cơ sở để đánh giá kết quả của các đơn vị tham gia ngoại kiểm và hiệu quả của chương trình ngoại kiểm. Vì thế, các mẩu phải đảm bảo chất lượng và gần giống với các mẫu thông thường; đáp ứng các tiêu chuẩn của mẫu ngoại kiểm dành cho thực hành lâm sàng.

\section{KẾT LUÂ̂N}

Quy trình sản xuất mẫu hồng cầu và huyết thanh cung cấp cho chương trình ngoại kiểm truyền máu đáp ứng tiêu chuẩn ISO/IEC 17043: 2010 được hoàn thiện so với quy trình sản xuất trước đây.

Mẫu đạt độ đồng nhất giữa tất cả các mẫu. Mẫu đạt độ ổn định trong điều kiện vận chuyển thử nghiệm tối thiểu đến ngày thứ 7 . Mẫu đat đô ổn định dài hạn từ ngày 0 đến ngày 49. Mẫu đạt độ vồ trùng đến ngày 14.

LỜI CÁM ON. Chúng tôi gứi lời cảm ơn Đại học $Y$ dược đã tài trợ để thực hiện nghiên cứu này.

TÀI LIẸU THAM KHẢO

1. Quyết định số $316 / T$ Tg (2016). Phê duyêt đề án tăng cường năng lực quản lý chất lượng xét 
nghiệm y hơc giai đoạn 2016 - 2025.

2. Tiêu chuấn quốc gia TCVN ISO/IEC 17043 (2011). Đánh giá sư phù hợp - Yêu câuu chung đối với thử nghiệm thành thạo. Nhà xuất bản Hà Nôii, pp. $9-10$.

3. Hoàng Thị Hà Anh (2014). Xây dựng quy trình sản xuất mẫu ngoại kiểm đánh giá chất lượng phòng thí nghiêm huyết thanh hoc HIV, pp.48 - 53.

4. Tîêu chuẩn Việt Nam TCVN 7366:2011 (ISO GUIDE 34:2009) (2011). Yêu cầu chung về năng lực của nhà sản xuất mâu chuẩn, tr $17-18$.

5. Deom A, EI Aouad R, Heuck CC, Kumari S, Lewis SM, Uldall A \& World Health Organization
(1999). Requirements and guidance for external quality assessment schemes for health laboratories.

6. World Health Organization (WHO) (2004). External quality assessment of transfusion laboratory practice. Guidelines on establishing an EQA scheme in blood group serology. Geneva, pp. $27-33$.

7. Yu Y, Ma C, Feng $Q$, Chen $X$, et al (2013). Establishment and performance assessment of preparation technology of internal quality control products for blood transfusion compatibility testing, pp.3-6.

\title{
NGHIÊN CỨU KIẾN THỨC, THỰC HÀNH VỀ PHÒNG VÀ PHÁT HIÊN SỚM UNG THƯ VÚ Ở PHỤ NỮ 18-60 TUỔI TẠI THÀNH PHỐ CẦN THO' NĂM 2020
}

\author{
Nguyễn Minh Phương ${ }^{1}$, Lê Thị Kim Định², \\ Lê Thị Ngọc Thảnh ${ }^{2}$, Đinh Thanh Nam², Lê Thị Bích Tuyên ${ }^{2}$
}

TÓM TẮT

Đặt vấn đề: Kinh nghiệm của nhiều quốc gia trên thế giới cho thấy việc tầm soát và phát hiện càng sớm sẽ giúp điều trị bệnh càng đơn giản, hiệu quả điều trị càng cao, chi phí điều trị càng thấp. Như vậy, kiến thức và thực hành phòng và phát hiện sớm ung thư vú có ý nghĩa thực hiện đối với phụ nữ trong giai đoạn hiện nay. Mục tiêu: Xác định tỳ lệ kiến thức, thực hành đúng vể phòng và phát hiên sớm ung thư vú ở phụ nữ 18-60 tuổi tại thành phố Cần Thơ năm 2020. Đổi tượng và phướng pháp nghiên cứu: Nghiên cứu mô tả cắt ngang 286 phụ nữ 18-60 tuổi tại thành phố Cần Thơ từ tháng 5 năm 2020 đến tháng 9 năm 2020. Phỏng vấn trực tiếp để thu thập thông tin về kiến thức, thực hành về phòng và phát hiện sớm ung thư vú. Nội dung kiến thức gồm 3 nội dung chính là kiến thức về bệnh ung thư vú, các biện pháp phòng ngừa bệnh ung thư vú, kiến thức về phát hiện sớm ung thư vú. Xữ lý số liêu bằng phân mêm SPSS 20.0. Kêtt quả: tỷ lệ kiến thức và thực hành đúng về phòng và phát hiện sớm ung thư vú lần lượt là $32,5 \%$ và 19,9\%. Kết luâan: Kiến thức và thực hành về phòng và phát hiện sớm ung thư vú ở phư nữ 18-60 tuổi tại thành phố Cần Thơ khá thấp. Do đó, lãnh đạo Sở Y tế cần phối hợp bệnh viện có những biện pháp can thiệp phù hợp tăng cường kiến thức và thực hành về phòng và phát hiện sớm ung thư vú ở phụ nữ 18-60 tuổi.

Tư khóa: phòng và phát hiện sớm ung thư vú, kiến thức thực hành

\footnotetext{
${ }^{1}$ Trường Đại học Y dược Cần Thơ

²Bệnh viện Phụ sản thành phố Cần Thơ

Chịu trách nhiệm chính: Nguyễn Minh Phương

Email: nmphuong@ctump.edu.vn

Ngày nhận bài: 26.10.2020

Ngày phản biện khoa học: 26.11.2020

Ngày duyệt bài: 7.12.2020
}

\section{SUMMARY \\ KNOWLEDGE, PRACTICE OF PREVENTION AND DETECTION EARLY WITH BREAST CANCER IN WOMEN 18-60 YEARS AT CAN THO CITY IN 2020}

Background: Experience of many countries around the world shows that the earlier screening and detection will help to treat the disease as simple, the higher the effectiveness of treatment, the lower the cost of treatment. Thus, knowledge and practice of prevention and early detection of breast cancer have implications for women in the current period. Objectives: To determine the rate of knowledge and correct practice on breast cancer prevention and early detection among women 18-60 years old in Can Tho city in 2020. Objects and research methods: A cross-sectional study was conducted on 286 women 18-60 years in Can Tho city from May 2020 to September 2020. The variables of knowledge and practice for breast cancer prevention and early were interviewed directly. Content of knowledge and practice included 3 main contents: breast cancer, breast cancer prevention measures and early detection of breast cancer. Data was analyzed by SPSS software with 20.0 version. Results: the percentage of correct knowledge and practice on breast cancer prevention and early detection were $32,5 \%$ and $19,9 \%$ respectively. Conclusion: Knowledge and practice on prevention and early detection of breast cancer among women 18-60 years old in Can Tho city is quite low. Therefore, leaders of the Department of Health need to coordinate with the hospital to have appropriate interventions to increase knowledge and practice on prevention and early detection of breast cancer in women $18-60$ years.

Keywords: breast cancer prevention and early detection, knowledge and practice

\section{I. ĐăT VẤN ĐỀ}

Theo thống kê của Tổ chức $Y$ tế Thế giới (WHO), ước tính năm 2018 trên toàn thế giới sẽ 